НАДЫРШИН Тимур Маратович

Институт этнологических исследований им. Р.Г. Кузеева - обособленное структурное подразделение Уфимского федерального исследовательского центра Российской академии наук

г. Уфа, Россия

timurimp@mail.ru

\section{ПРОБЛЕМЫ АНТРОПОЛОГИЧЕСКОГО ИЗУЧЕНИЯ ИСТОРИЧЕСКОГО ОБРАЗОВАНИЯ В РОССИЙСКОЙ ШКОЛЕ}

Расширение предметного поля антропологии и этнографического метода в российской науке в последние годы актуализирует необходимость изучения образовательного пространства. С другой стороны, в условиях становления Федерального государственного стандарта общего образования требуется рефлексия учеными и учителя школьной повседневности. Применение культурной антропологии для изучения исторического образования в российской школе дает возможность для подобной рефлексии. В данной статье, подготовленной в рамках проекта РФФИ «История глазами субъектов образования. Антропологический анализ культурной трансмиссии», приведены теоретические доказательства того, что история выполняет функцию культурной трансмиссии, а также на основе контркультурного контура образования, введенного американским антропологом Ж. Генри, предложен разработанный автором инструментарий антропологического исследования, применимый для анализа исторического образования в средней школе.

Ключевые слова: слова: антропология образования, история в школе, культурная трансмиссия, историческая память, школьная повседневность, Жюль Генри, историческое образование результаты обучения, отношение к истории, российская школ

Для цитирования: Надыршин Т.М. Проблемы антропологического изучения исторического образования в российской школе. Историческая и социально-образовательная мысль. 2018. Том. 10. № 6-1. c. 186-195.

doi: 10.17748/2075-9908-2018-10-6/1-186-195.

Timur M. NADYRSHIN Kuzeev Institute of Ethnological Studies Subdivision of FSBSU Ufa Federal Research Center of RAS Ufa, Russia timurimp@mail.ru

\title{
PROBLEMS OF ANTHROPOLOGICAL STUDY OF HISTORICAL EDUCATION IN RUSSIAN SCHOOL
}

The expansion of the subject field of anthropology and the ethnographic method in Russian science in recent years actualizes the need to study the educational space. On the other hand, in the conditions of the formation of the Russian State standard and the programs of secondary general education, reflection is required by scientists and the teacher of school everyday life. The use of cultural anthropology for the study of historical education in the Russian school provides an opportunity for such reflection. This article was prepared within the framework of the RFBR project "History through the Eyes of Education Subjects. Anthropological Analysis of Cultural Transmission". It provides theoretical evidence that history performs the function of cultural transmission, as well as on the basis of the counter-cultural contour of education introduced by American anthropologist J. Henry, proposed by the author's tool of anthropological research applicable for the analysis of historical education in school.

Key words: anthropology of education, history at school, cultural transmission, historical memory, school daily life, Jules Henry, historical education, learning outcomes, relation to history, Russian school

For citation Nadyrshin T.M. Problems of anthropological study of historical education in Russian school. Historical and Social-Educational Idea. 2018. Vol. 10. No. 6-1. Pp. 186-195. doi: 10.17748/2075-9908-2018-10-6/1-186-195. (in Russ)

Благодарность. Статья подготовлена при поддержке РФФИ Проект № 18-49-020010: «История глазами субъектов образования. Антропологический анализ культурной трансмиссии».

\section{Acknowledgement. The article was prepared with the support of the Russian Foundation for Basic Research Project No. 18-49-020010: "History through the Eyes of the Subjects of Education. Anthropological Analysis of Cultural Transmission".}




\section{Введение}

С точки зрения антропологии обучение в обществе выполняет функцию культурной трансмиссии (передачи). Как отмечает американский антрополог Л. Уайт, обучение это «способ, которым общество навязывает индивиду свои обычаи, верования, идеалы и модели поведения» [1]. Государства используют обучение в качестве инструмента для формирования национальной идентичности, социализации и инкультурации граждан самых разных групп населения [2]. Внутри обучения также существует множество компонентов, которые выполняют функцию культурной трансмиссии. Эти компоненты можно разделить по самым разным категориям: системы дисциплины, системы поощрения и наказания, предметы в школе, физическое воспитание и т.д. Все эти компоненты мало сводимы к какой-то одной классификации. Один из возможных ракурсов антропологического исследования обучения - это рассмотрение того, как отдельный предмет в школе обеспечивает трансмиссию культуры. В данной работе фокус анализа сосредоточен на истории в школе.

Статья преследует две цели. Первая цель - выделить аргументы в пользу тезиса, который гласит, что история в школе выполняет функцию культурной трансмиссии. Вторая цель - предложить инструментарий антропологического исследования, применимый для анализа исторического образования в средней школе.

Расширение предметного поля антропологии и этнографического метода в российской науке в последние годы актуализирует необходимость изучения образовательного пространства. С другой стороны, в условиях становления Федерального государственного стандарта общего образования требуется рефлексия учеными и учителя школьной повседневности. Новизна работы заключается в создании инструментария исследования, который был бы применим для анализа исторического образования в российской школе. Инструментарий состоит из 92 контрольных вопросов, которые дают возможность исследовать значительное количество аспектов исторического образования с позиции антропологического подхода.

В мировой и российской науке уже были проведены исследования, антропологически рассматривающие роль истории в школе. В работе Д. Уиллса анализируется влияние учебной программы по истории на отношение школьников к расовому вопросу в США. Статья заканчивается рекомендациями по созданию программы, не нарушающей права обеих расовых групп [3]. В книге М. Ферро проанализировано, как преподается история в разных странах мира. В ней автор уделяет внимание нескольким ключевым проблемам, которые характерны для исследуемых им программ истории в разных государствах. Исходя из того, что в каждой стране история этноцентрична, то создание мировой, тотальной истории не осуществимо. Однако даже этноцентризм имеет разные формы, что позволяет ученым выделить ценности общества [4].

Антропологическое изучение истории в школе неизбежно сталкивается с проблемой анализа исторической памяти. Историческая память общества является важной частью персональной и коллективной идентичности. Отечественная научная литература, посвященная данному аспекту, может быть разделена на две категории. Первая категория - это работы, акцентирующие внимание на важности сохранения исторической памяти школьников. Значительная часть этих исследований предлагает определенную программу и методы для практикующих педагогов. Весомая доля этих работ посвящена проблеме актуализации сохранения памяти о Великой Отечественной войне среди школьников $[5 ; 6]$.

Во вторую категорию входят работы, направленные на этнографическое или социологическое исследование аспектов изучения памяти среди школьников. В исследовании И.В. Кутыковой и О.В. Халлисте делается вывод, что на данный момент наблюдаются две основные тенденции к нечеткости в оценках старшеклассниками исторических событий: с одной стороны, собственной позиции в отношении прошлого своего народа, своей страны, а с другой - государственной позиции в данном вопросе [6]. 
Очень подробное исследование М.А. Красноборова посвящено проблемам формирования исторической памяти и территориальной (локальной) идентичности у старшеклассников. Важный вывод, который делает автор, - это то, что школьные уроки являются основным источником формирования исторической памяти. С другой стороны, каркасом локальной и региональной идентичности выступает как раз семейная история [7].

Социологическая работа А.Н. Макарова, посвященная исторической памяти магнитогорских школьников о Великой Отечественной войне, фиксирует неутешительные выводы: во-первых, у современных школьников слабо сформировано представление о героических страницах в истории Великой Отечественной войны; во-вторых, чувство гордости за народ-победитель, вполне справедливое причисление себя к поколению наследников победителей уживаются с отрывочными сведениями (или же с их отсутствием) о судьбе своих предков в годы войны [8].

Результаты исследования А.В. Селезневой показывают, что революционные события 1917 г. вызывают у молодых людей противоречивые чувства: они испытывают к ним одновременно и положительные, и отрицательные эмоции. Событийный ряд представлений молодежи о революции достаточно скуден и стереотипен. Школьники не обладают сколь-нибудь конкретными знаниями об этих событиях, их причинах и последствиях, наиболее выдающихся деятелях. Они слабо осведомлены о том, как отражаются революционные события в произведениях культуры (литературных произведениях и кинофильмах). Уровень когнитивной сложности их представлений достаточно низкий [9].

Таким образом, программа исторического образования в школе неизбежно опирается на определенные фокусы в обучении. Эти фокусы этноцентричны и опираются на представления общества о прошлом.

Данная работа имеет следующую структуру: вначале приведены теоретические доказательства того, что история выполняет форму трансмиссии (передачи) культуры. В следующем разделе охарактеризованы современные концептуальные основы российского исторического образования. Первый раздел, по сути, говорит о существующих перекосах в российском историческом образовании до принятия ФГОС, второй раздел коротко рассматривает, как в новом историко-культурном стандарте предлагается ликвидировать эти перекосы. В третьем разделе предлагается инструментарий исследования для осмысления исторического образования с помощью культурной антропологии.

\section{История как форма культурной трансмиссии}

Попробуем последовательно ответить на вопрос, почему история выполняет функцию культурной трансмиссии, а также в некоторых случаях представить рассуждения по поводу преподавания истории в российской школе.

Во-первых, урок истории формирует национальную и культурную идентичность школьников. Это связано с тем, что основная часть усваиваемого школьниками материала посвящена Отечественной истории, а уже затем - другим государствам.

Во-вторых, на занятиях по отечественной и мировой истории поурочными планами, учебниками выделяются те страны и территории, которые имеют важную значимость для государства. В России традиционно в учебниках истории доминирует европоцентристский подход. В список «великих держав» попадают Англия, США, Франция, Германия. Другим государствам уделено значительно меньше места. Такая ситуация была характерна и для дореволюционного, и для советского периода. Как результат - в учебниках уделено мало места государствам и территориям Азии, Африки и Латинской Америки. В современных геополитических условиях «разворот на Восток», декларируемый руководством России, необходимо перенести в поле исторических школьных нарративов. Такие же «географические акценты» существуют и в России. Основные события, разворачивающиеся в стране, происходят в двух столицах. При подготовке учебников, стандартов образования необходимо учитывать существующие программы развития других регионов Российской Федерации для выработки положительного имиджа этих территорий.

В-третьих, урок истории формирует интерес к тем или иным областям жизни. Всегда есть место перекосу: в российском образовании истории политики, войн и междуна- 
родных отношений уделено на порядок больше места, чем другим областям, составляющим важную часть жизни людей: повседневность, экономическое развитие, культура, наука и техника, образование, религия и ряд других областей. Внутренние процессы, переход к рыночной экономике должны отражаться и в историческом образовании. Исходя из предыдущего пункта, необходимо сказать, что этот предмет формирует перечень «героев». В школе на уроках в России традиционно основными героями и носителями человеческого прогресса выступают в первую очередь правители, государственные деятели, полководцы, революционеры и т.д. Героям других родов деятельности, как, например, предпринимателям, ученым, философам, религиозным деятелям, представителям рабочих профессий, на страницах школьных учебников истории уделяется значительно меньше места.

B-четвертых, урок истории имеет большое значение для понимания существующей ситуации в мире. И в этом отношении принципиально, как выстроено повествование учителя, учебников и других источников, с которыми школьник сталкивается в условиях преподавания. Например, какие причины являются доминирующими при объяснении основных событий истории. В зависимости от позиции субъектов образовательной деятельности тем или иным факторам уделяется большее внимание. Великие исторические личности, природа, климат, география, менталитет, демография, наука, техника, экономика, Божий промысел, классовая борьба, случайные события - все эти и другие первопричины могут превозноситься учителями, родителями и авторами учебников.

B-пятых, история формирует гордость школьников за определенные временные диапазоны. Согласно Ж. Генри, их существует пять: происходящее в данный момент, современность, ближайшее прошлое, далекое прошлое, мифическое прошлое [10]. Однако подобные временные охваты достаточно сложно оценить для антрополога. Гораздо проще разбить исторические этапы развития той или иной территории на определенные промежутки и выявить степень интереса школьников к этим этапам. Такими хронологическими датами в России могут выступать: революция 1917 г., Великая Отечественная война, Киевская Русь и т.д. Иерархия интереса школьников к таким «временным срезам» позволяет выявить, какие периоды прошлого вызывают самый большой отклик у школьников.

B-шестых, урок истории влияет на формирование определенной системы политических, культурных ценностей школьника. Например, те или иные политические режимы могут выступать на страницах учебников отрицательно, нейтрально или положительно. Поступки героев истории неизбежно будут оцениваться учителями, авторами учебников, родителями, фильмами, книгами и другими источниками исторического знания, с которым ученик сталкивается. И это неизбежно будет накладывать отпечаток на культурную память школьника.

\section{Концептуальные основы современного российского исторического образования}

Важной перспективой для развития исторического образования в России является создание историко-культурного стандарта. Новый стандарт выделяет следующие концептуальные основы, на которых должно базироваться современное историческое образование:

1. Культурно-антропологический подход (постижение перипетий «рядовых граждан», сквозь судьбы которых могут быть показаны социальные и политические процессы; освещение проблем духовной и культурной жизни России);

2. Этнокультурный компонент: история страны через историю регионов (акцент на многонациональном и поликонфессиональном составе населения страны как важнейшей особенности отечественной истории);

3. Выработка сознательного оценочного отношения к историческим деятелям, процессам и явлениям;

4. Выполнение учебником функции навигатора [11].

Во многом перекликаются положения проекта историко-культурного стандарта с образовательными стандартами. В последнем акценты преподавания истории расстав- 
лены достаточно четко. Например, одной из целей урока истории является «формирование важнейших культурно-исторических ориентиров для гражданской, этнонациональной, социальной, культурной самоидентификации личности, миропонимания и познания современного общества на основе изучения исторического опыта России и человечества» [12].

В новых учебных планах структура учебника, темы параграфов существенно пересмотрены. Взять, к примеру, учебник по истории России для 7-х классов, подготовленный коллективом авторов: Н.М. Арсентьевым, А.А. Даниловым, И.В. Курукиным, А.Я. Токаревой. В отличие от предыдущих учебников для 7-х классов больше внимания теперь уделено таким проблемам, как хозяйство, экономическое развитие, этническая структура России, роль религии в жизни общества [13].

Подводя итог, нужно отметить, что историко-культурный стандарт и ФГОС должны стать основой для распределения акцентов при создании школьных нарративов по предмету. Подобный пробел ликвидируется теперь в учебниках по Отечественной истории. Важной задачей сейчас является создание региональных учебников по истории на основе историко-культурного стандарта.

\section{Инструментарий для антропологического анализа истории в школе}

«Обыкновенный» урок, проведенный «обыкновенным» учителем, «обыкновенным» детям не позволит сразу выявить глубинные антропологические выводы. Это связано с тем, что школьная повседневность нам кажется «обыденной» и не в состоянии обеспечить «культурный шок» и какие-то очевидные антропологические выводы. Исходя из этого, важно определить предметы внимания, которые бы дали возможность изучить повседневность истории в школе. Поэтому инструментарий антропологического анализа должен состоять из многочисленного количества контрольных вопросов, на которые антрополог должен ответить, анализируя отдельные компоненты составляющие «повседневность» исторического образования.

В представленном инструментарии вопросы для анализа объединены в определенные блоки. Эти блоки представляют собой основные проблемы антропологического изучения исторического образования в российской школе. Данные вопросы и проблемы основаны на модели кросскультурного контура образования, разработанного американским культурным антропологом, учеником Рут Бенедикт, Жюлем Генри [14]. Его исследования школы в американском обществе являются классическими для антропологии и не потеряли своей научной значимости и по сей день. Таких проблем нами было выделено семь:

Первая проблема - это то, на чем образование концентрируется, иными словами, программа (фокус) обучения.

Вторая проблема - то, каким образом происходит обучение.

Третья проблема - ответ на вопрос, что представляет собой учитель.

Четвертая проблема - реакция учеников на образовательный процесс.

Пятая проблема - реакция учителя на образовательный процесс.

Шестая проблема - препятствия, мешающие школьнику получить объем информации от учителя в полной мере.

Седьмая проблема - связь между целями обучения и их результатами.

\section{Вопросы для изучения программы (фокуса) обучения.}

1. Как представлено взаимодействие человека с природой?

2. Как объясняется влияние географических условий на жизнь общества?

3. Какие существуют пространственно-географические акценты на уроках истории?

- Где происходят основные исторические события?

- Каким странам, территориям, городам, другим географическим объектам уделено больше внимания? 
- История каких стран, территорий, городов, других географических объектов вызывает наибольший интерес?

- Какова доля региональной истории?

- Насколько интересна региональная история субъектам образования?

$4 . \quad$ Какие существуют временные акценты на уроках истории?

- Какие периоды выступают как период максимального благоденствия?

- Какие периоды истории вызывают наибольшую гордость?

- Какие периоды истории вызывают стыд?

- Какие периоды истории вызывают наибольший интерес у субъектов образования?

5. Какое значение вкладывается в понятие прогресса?

6. Прогресс в каких областях человеческой деятельности является наиболее важным?

7. Кто является основным генератором изменений в истории того или иного общества?

- Представители каких возрастных групп (пожилые, зрелые люди, молодежь) чаще всего представлены носителями прогресса или тех или иных идеалов?

- Представителям каких возрастных групп уделено больше внимания?

- Представители каких категорий социальной структуры (слои, сословия, классы) чаще всего представлены носителями прогресса или тех или иных идеалов?

- Представителям каких категорий социальной структуры уделено больше внимания?

- Представители каких категорий социальной структуры вызывают наибольший интерес и уважение?

- Представители каких видов деятельности чаще всего представлены носителями прогресса или тех или иных идеалов?

- Представителям каких видов деятельности уделено больше внимания на уроках истории?

- Представители каких видов деятельности вызывают наибольший интерес и уважение?

- Как оценивается роль отдельных правителей или групп в истории?

- Чему уделено большее внимание - словам или поступкам героев истории?

8. Чем объясняются проблемы в истории государства?

9. Какие факторы представлены доминирующими: великие исторические личности, природа, климат, география, менталитет, демография, наука, техника, экономика, случайные события и т.д.?

10. Кто или что чаще всего представлено положительным, другом, союзником?

11. Кто или что чаще всего является отрицательным, оппонентом, врагом?

12. Как представлены определенные ценности на истории?

13. Какие добродетели и пороки упоминаются в условиях преподавания истории? Какова их интерпретация в условиях преподавания истории?

14. Что отнесено к понятиям «моральное» и «аморальное»?

15. Как трактуется понятие патриотизма?

16. К К чему привязано понятие патриотизма: территория, народ, культура, ценности, символы и т.д.?

17. Гордость за какие исторические события испытывают субъекты образования: победы в войнах, приобретение новых территорий, благотворительность, боевые подвиги, успехи в экономике, культуре, науке, спорте и т.д.?

18. Насколько уделено внимание политическим процессам в обществе?

19. Как оцениваются те или иные политические режимы и формы правления и их влияние на историю: монархия, тоталитаризм, демократия и т.д.?

20. Насколько уделено внимание этническим процессам в обществе?

21. Как оценивается этнический фактор в истории?

22. Насколько уделено внимание религиозным процессам в обществе? 
23. Как оценивается религиозный фактор в истории?

24. Насколько уделено внимание экономическим процессам в обществе?

25. Как оценивается экономический фактор в истории?

26. Насколько уделено внимание научно-технологическим процессам в обществе?

27. Как оценивается научно-технологический фактор в истории?

28. Какие практические советы и руководства к действию заметны в условиях преподавания истории?

\section{Вопросы для анализа процесса обучения.}

1. К Какие методы обучения и с какой частотой применяются?

$2 . \quad$ Какие используются способы поощрения?

3. Какие используются способы наказания?

4. Какие используются средства обучения?

$5 . \quad$ Какие явные и скрытые угрозы применяются?

6. Каково место технических устройств на уроке?

7. С какой частотой и как применяются иллюстративные, текстовые, аудио- и видеоматериалы?

8. Ч Ч чаще всего делают учащиеся: смотрят, слушают, говорят, работают самостоятельно и т.д.?

9. Что чаще всего делают учителя: смотрят, слушают, говорят и т.д.?

10. Какие вопросы чаще всего задаются учителем?

11. Кому чаще всего адресованы вопросы?

12. Как часто учитель задает вопросы?

13. Какие вопросы чаще всего задаются учителю?

14. От кого чаще всего поступают вопросы?

15. К Как часто учитель слышит вопросы от учеников?

16. Какова цель вопросов?

17. Есть ли место дискуссии на уроке, относительно каких тем и вопросов?

18. Какие методы физического воздействия используются?

19. Насколько представлены методы, ориентированные на работу нескольких человек?

20. Каково содержание сообщений учащихся?

\section{Вопросы для анализа учителя.}

1. Какой у учителя пол, возраст, семейное положение?

2. К Какой социальной группе принадлежит учитель?

3. Какая у учителя этническая самоидентификация?

4. Как учитель относится к религии?

5. С какими группами учеников учитель в первую очередь взаимодействует по полу, социальной группе, национальности, религиозной принадлежности?

6. Какие у учителя имеются личные и профессиональные достижения?

7. Какие элементы одежды и внешности учителя являются специфичными для данной культуры?

\section{Вопросы для анализа проблемы реакции учащихся на образование.}

1. Какая доля учащихся принимает знания?

2. Какая доля учащихся отрицательно относится к уроку?

3. Какой доле учащихся скучно на уроке?

4. Насколько часто учащиеся идут на конфликт с учителем, другими учащимися на уроке?

5. Как выражается отрицательное отношение (смех, отвлечения на другие виды деятельности, опоздания, игнорирование замечаний)? 
6. В чем выражается юмор на уроке?

7. Как выражены физические действия учащихся на уроке?

8. Какую одежду надевают учащиеся на урок? Насколько она соотносится с установленными правилами школьной формы в учреждении?

9. Какая доля учащихся перевыполняет стандартный объем работы?

10. Есть ли место исправлениям учителя со стороны школьников?

11. Как происходит взаимодействие с учителем на перемене до и после урока?

12. Насколько един классный коллектив в конфликтных ситуациях?

13. Как учащиеся обращаются к учителю?

14. Есть ли место обману на уроке? У каких групп, с какой периодичностью и в чем обман выражается?

\section{Вопросы для анализа проблемы реакции учителя на образование.}

1. Какова заинтересованность учителя в своей работе?

2. Какова реакция учителя на провокации школьников?

3. Какова реакция учителя на конфликтные ситуации внутри коллектива на уроке?

4. Какие правила учитель установил на уроке, помимо тех, что приняты в школе?

5. Какова реакция учителя на выполнение установленных правил на уроке?

6. Какова реакция учителя на нарушение установленных правил на уроке?

7. Какие формы вознаграждения используются учителем?

8. К К акие действия учащихся вызывают раздражение учителя?

9. Как учитель обращается к ученикам?

10. Какие особенности характерны для речи учителя?

11. Как учитель использует юмор на уроке?

12. Как учитель относится к самооценке учащихся?

13. Как меняется содержание получаемых учащимися знаний в зависимости от их пола, возраста или других параметров?

\section{Вопросы для анализа проблемы препятствий в обучении.}

1. Как методы обучения затрудняют получение знаний учащимися?

$2 . \quad$ Как ошибки в распределении времени затрудняют получение знаний учащимися?

3. Как качество оборудования затрудняет получение знаний учащимися?

4. Как поведение учителя затрудняет получение знаний учащимися?

5. Как стереотипы учителя затрудняют получение знаний учащимися?

6. К К К ошибки учителя затрудняют получение знаний учащимися?

7. Как незнание учителем материала в ряде вопросов затрудняет получение знаний учащимися?

Вопросы для анализа проблемы связи между целями обучения и их результатами.

1. Как выполняются цели и задачи, определенные учителем?

2. Как выполняются цели и задачи, определенные документами, регулирующими образовательный процесс?

3. Какие могут быть выделены противоречия между пониманием учителя, учебников и документов, регулирующих преподавание истории?

Подводя итог вышесказанному, нужно отметить, что первое, на что следует обратить свой взор ученому, который начал антропологическое чтение истории в школе, - это тексты: учебник, атлас, рабочая тетрадь. Второе, на что следует направить свой взгляд, это урок. Эти базовые источники помогут определить, какой отражается культура в условиях преподавания истории. 
Для чего могут быть полезными вышеперечисленные антропологические вопросы? Во-первых, ответы на них могут приблизить антрополога к более глубокой рефлексии школьного пространства в частности и российской культуры в целом. Во вторых, они позволят ученому рассмотреть, насколько «прививаются» новые стандарты исторического образования в школе.

Несомненно, что существующие стандарты, натолкнутся на определенное «сопротивление». Это «сопротивление» связано с такими факторами влияния на историческое образование, как инерция существующего положения исторического образования, социально-культурный облик современного учителя, влияние СМИ, европоцентризм отечественной исторической науки.

Дальнейшие исследования проблемы и применение вышеизложенного инструментария позволят собрать данные о форме преподавания истории в школе и в итоге сформулировать методические рекомендации для учителей истории, чтобы они изменили направленность развития учеников при помощи исторического знания. За счет правильно подобранных нарративов учителя могут перераспределить акценты, так как этого требуют современные условия.

\section{БИБЛИОГРАФИЧЕСКИЕ ССЫЛКИ}

1. Уайт Л. Государство-Церковь: его формы и функции. // Антология исследований культуры. Т. 1. Интерпретация культуры / отв. ред. Л.Я. Левит. - СПб.: Университетская книга, 1997. - С. 304.

2. Foley D. The Rise of Class Culture Theory in Educational Anthropology // A companion to the anthropology of education / B.A. Levinson [и др.]. - Oxford: Wiley-Blackwell, 2011. - P. 88.

3. Wills J.S. Who Needs Multicultural Education? White Students, U.S. History, and the Construction of a Usable Past // Anthropology \& Education Quarterly. - 1996. - Vol. 27. №. 3. - Pp. 365-389.

4. Ферро М. Как рассказывают историю детям в разных странах мира / Пер. с фр. - М.: Высшая школа, 1992. - 351 с.

5. Попова А.С. Историческая память о Великой Отечественной войне в процессе воспитания младших школьников // Педагогическое образование на Алтае. - 2015. - № 2. - С. 36-39; Рогов Д.В. Феномен исторической памяти народа и его отражение в проектной деятельности школьников (на примере истории Ленинградской битвы // Образование: ресурсы развития. Вестник ЛОИРО. - 2015. - № 1. - С. 5-8.

6. Кутыкова И.В., Халлисте О.В. Историческая память современных школьников России и Эстонии: социологический анализ // Вестник СПбГУ. - 2015. Сер. 12. - Вып. 3. - С. 175.

7. Красноборов М.А. Источники конструирования исторической памяти пермских школьников (по материалам социологического исследования) // Вестник Пермского университета. Философия. Психология. Социология. - 2017. - № 3 (31). - С. 486-496.

8. Макаров А.Н. «И очень хочется, чтобы каждый из нас так же любил Родину, как и наши прадеды»: опыт исследования исторической памяти школьников Магнитогорска о Великой Отечественной войне // Гороховские чтения. Сб. мат-лов 6-й регион. музейн. конф. - 2015. - С. 452 456.

9. Селезнева А.В. Представления о Революции 1917 года в политическом сознании российской молодежи // Гуманитарные науки. Вестник Финансового университета. - 2018. - Т. 8. № 1 (31). - C. 32-40.

10. Henry J. A Cross-Cultural Outline of Education // Current Anthropology. - 1960. - Vol. 1. № 4. - P. 269.

11. Историко-культурный стандарт. URL: https://минобрнауки.рф/документы/3483/файл/2325/13.07.01.-Проект_Историкокультурного_стандарта.pdf

12. Федеральный государственный образовательный стандарт основного общего образования (5-9 кл.). URL: https://xn--80abucjiibhv9a.xn-p1ai/\%D0\%B4\%D0\%BE\%D0\%BA\%D1\%83\%D0\%BC\%D0\%B5\%D0\%BD\%D1\%82\%D1\%8B/938

13. История России. 7 класс: Учебник для общеобразовательных организаций в 2 ч. / Под.ред. А.В. Торкунова. - М.: Просвещение, 2016.

14. Henry J. Ibid. - Pp. 267-305. 


\section{REFERENCES}

1. White L. Gosudarstvo-Tserkov': ego formy i funktsii [The State Church in Modern Society]. Antologiya issledovaniy kul'tury. V. 1. Interpretatsiya kul'tur. otv. red. Levit L.Ya., Saint Petersburg.: Universitetskaya kniga, 1997. P. 304. (in Russian)

2. Foley D. The Rise of Class Culture Theory in Educational Anthropology. A companion to the anthropology of education. В. A. Levinson [и др.]. Oxford: Wiley-Blackwell, 2011. P. 88.

3. Wills J.S. Who Needs Multicultural Education? White Students, U.S. History, and the Construction of a Usable Past. Anthropology \& Education Quarterly. 1996. Vol. 27. No. 3. Pp. 365-389.

4. Ferro M. Kak rasskazyvayut istoriyu detyam $v$ raznykh stranakh mira: [The Use and Abuse of History: Or How the Past is Taught to Children]. Moscow.: Vysshaya shkola, 1992. 351 p. (in Russian)

5. Popova A.S. Istoricheskaya pamyat' o Velikoy Otechestvennoy voyne v protsesse vospitaniya mladshikh shkol'nikov [The historical memory of the Great Patriotic War in the process of educating younger students]. Pedagogicheskoe obrazovanie na Altae. 2015. No. 2. Pp. 36-39. (in Russian); Rogov D.V. Fenomen istoricheskoy pamyati naroda i ego otrazhenie v proektnoy deyatel'nosti shkol'nikov (na primere istorii Leningradskoy bitvy) [The phenomenon of the historical memory of the people and its reflection in the project activities of schoolchildren (on the example of the history of the Leningrad battle)]. Obrazovanie: resursy razvitiya. Vestnik LOIRO. 2015. No.1. Pp. 5-8. (in Russian)

6. Kutykova I. V., Khalliste O. V. Istoricheskaya pamyat' sovremennykh shkol'nikov Rossii i Estonii: sotsiologicheskiy analiz [The historical memory of modern schoolchildren of Russia and Estonia: a sociological analysis]. Vestnik SPbGU. 2015. V. 12. No.3. P. 175. (in Russian)

7. Krasnoborov M.A. Istochniki konstruirovaniya istoricheskoy pamyati permskikh shkol'nikov (po materialam sotsiologicheskogo issledovaniya) [Sources of constructing the historical memory of Perm schoolchildren (based on a sociological study)]. Vestnik Permskogo universiteta. Filosofiya. Psikhologiya. Sotsiologiya. 2017. No.3 (31). Pp. 486-496. (in Russian)

8. Makarov A.N. «I ochen' khochetsya, chtoby kazhdyy iz nas tak zhe lyubil Rodinu, kak i nashi pradedy»: opyt issledovaniya istoricheskoy pamyati shkol'nikov Magnitogorska o Velikoy Otechestvennoy voyne [ «And I very much want each of us to love the Motherland as much as our greatgrandfathers»: the experience of studying the historical memory of Magnitogorsk schoolchildren about the Great Patriotic War]. Collection of materials of the sixth regional museum conference: Gorokhovskie chteniya. 2015. Pp. 452-456. (in Russian)

9. Selezneva A.V. Predstavleniya o Revolyutsii 1917 goda v politicheskom soznanii rossiyskoy molodezhi [Representations of the Revolution of 1917 in the political consciousness of the Russian youth]. Gumanitarnye nauki. Vestnik Finansovogo universiteta. 2018. V. 8. No.1 (31). Pp. 32-40.

10. Henry J. A Cross-Cultural Outline of Education. Current Anthropology. 1960. Vol. 1. No.4. P. 269.

11. Istoriko-kul'turnyj standart. [Historical and Cultural Standard] Available at: https://минобрнауки.рф/документы/3483/файл/2325/13.07.01.-Проект_Историкокультурного_стандарта.pdf

12. Federal'nyj gosudarstvennyj obrazovatel'nyj standart osnovnogo obshhego obrazovanija (5-9 kl.) [The Russian State standard and the programmes of secondary general education (5-9 classes)] Available at: https://xn--80abucjiibhv9a.xn-p1ai/\%D0\%B4\%D0\%BE\%D0\%BA\%D1\%83\%D0\%BC\%D0\%B5\%D0\%BD\%D1\%82\%D1\%8B/938

13. Istorija Rossii. 7 klass. Uchebnik dlja obshheobrazovatel'nyh organizacij v 2 ch. [Russian history. 7th grade. Textbook for educational organizations in 2 parts.] Ed. By A.V. Torkunov. Moscow: Prosveshhenie. 2016.

14. Henry J. A Cross-Cultural Outline of Education // Current Anthropology. 1960. Vol. 1. No. 4. Pp. 267305.

\section{Информация об авторе:}

Надыршин Тимур Маратович, младший научный сотрудник, отдел религиоведения, Институт этнологических исследований им. Р.Г. Кузеева - обособленное структурное подразделение ФГБНУ Уфимский федеральный исследовательский центр РАН,

г. Уфа, Россия

timurimp@mail.ru

\section{Information about the author:}

Timur M. Nadyrshin, Junior Researcher, Department of Religious Studies, Kuzeev Institute of Ethnological Studies - Subdivision of FSBSU Ufa Federal Research Center of RAS,

Ufa, Russia

timurimp@mail.ru 